\title{
Avaliação da formação de enfermeiros: o reflexo dos métodos de ensino-aprendizagem e pressupostos curriculares na prática profissional
}

\author{
Anete Maria Francisco \\ Maria Cristina Guimarães da Costa \\ Cássia Galli Hamamoto \\ Maria de Lourdes Marmorato Botta Hafner
}

Resumo: Pesquisa de egressos de graduação em Enfermagem, com abordagem quanti-qualitativa, cujo objetivo foi possibilitar o seu acompanhamento em relação à inserção no mercado de trabalho, continuidade de sua formação, além de contribuir para a reflexão sobre as relações entre teoria e prática e entre o mundo acadêmico e o mundo do trabalho, subsidiando a avaliação da formação acadêmica. Os sujeitos foram os egressos dos anos de 2007 a 2010 de um Curso de Enfermagem. $\mathrm{O}$ instrumento de coleta de dados foi um questionário sobre aspectos socioeconômicos, atuação e avaliação do curso e uma narrativa com aspectos de sua formação e vivência profissional. A análise quantitativa foi a partir de frequências absolutas e porcentagens e as narrativas, a partir do método de interpretação de sentidos. Como resultado, obtiveram-se respostas de $32 \%$ dos egressos, sendo que a maioria está inserida no mercado de trabalho, com alta empregabilidade na área e em serviços públicos, distribuídos igualmente na atenção primária e terciária, tendo cursado ou estando cursando uma pós-graduação. Observou-se que os pressupostos curriculares estão presentes no cotidiano dos egressos e que os métodos ativos de ensino-aprendizagem favorecem seu desenvolvimento profissional. Apontaram-se, como fragilidades, a dificuldade de lidar com a proposta do curso em formar profissionais comprometidos com o SUS, a adaptação às metodologias de ensino empregadas, a deficiência do aprendizado de procedimentos e pouco estímulo à pesquisa. Há necessidade de planejamento de estratégias para superá-las e, assim, reafirmar o compromisso com a formação profissional e a qualidade de vida da população.

Palavras-chave: Avaliação. Educação em enfermagem. Avaliação institucional.

Evaluation of formation of nurses: effect of methods of teaching-learning curriculum and assumptions in professional practice

Abstract: This research seeks to identify the insertion of the graduates in the job offers and continued education and to contribute to the debate on the relationship between theory and practice and between the academic world and the world of work both supporting the assessment of academic training. The subjects were graduates of nursing of the years 2007 to 2010 . The data collection instrument was a quantitative and qualitative questionnaire. Quantitative analysis was as absolute frequencies and percentages. Qualitative analysis used the method of interpretation of meanings. As a result, we obtained responses from $32 \%$ of the graduates. The most of them were inserted in the job market with high employability in the public services having attended or being enrolled in a postgraduate course. It was observed that the assumptions are present in the curriculum of graduates and active methods of teaching and learning foster their professional development. The weaknesses points were the difficulty of dealing with the course proposal to form professionals committed to the NHS, the adaptation to teaching methodologies employed, the deficiency of learning procedures and little incentive to research. These results suggest the necessity of planning strategies to overcome them, and thus reaffirm the commitment to training and the quality of peoples' life.

Key words: Evaluation. Nursing education. Institutional assessment. 


\section{Introdução}

As mudanças ocorridas no âmbito da graduação em Enfermagem têm acompanhado o contexto mundial de transformação de referenciais da educação e das políticas de saúde, apontando para a necessidade de reorientar a formação de enfermeiros, seus conteúdos curriculares, bem como as metodologias de ensino e capacitação de docentes, envolvidos em todo o processo, buscando formar o profissional que a sociedade contemporânea exige.

No Brasil, um dos reflexos do movimento de renovação da formação nesta área foi a elaboração das Diretrizes Curriculares para o Curso de Enfermagem pelo Ministério da Educação (BRASIL, 2001) que orientam as exigências para o profissional do século XXI.

Em consonância com as tendências mais proeminentes em atenção à saúde e em educação de profissionais de saúde, a Faculdade de Medicina de Marília (Famema) vem construindo uma trajetória no desenvolvimento e na implementação de novos modelos de formação desses profissionais desde a década de 1990.

O acúmulo de conhecimentos gerado pelas diversas atividades promovidas permitiu a elaboração de um novo projeto educacional que promoveu reforma curricular significativa nos Cursos de Medicina, adotando a aprendizagem baseada em problemas (ABP) e, no de Enfermagem, com a problematização, a partir de 1997 e 1998, respectivamente. A partir das avaliações de programas vinculados a esses projetos, em 2003, houve efetiva integração dos Cursos de Medicina e Enfermagem com a intenção de favorecer um currículo integrado e orientado por competência, organizando-se em duas unidades educacionais: Unidade Educacional Sistematizada (UES) e Unidade de Prática Profissional (UPP), utilizando-se, respectivamente, a $\mathrm{ABP}$ e a problematização.

Nesse sentido, o projeto pedagógico do Curso de Enfermagem da Famema se propôs a formar enfermeiros generalistas, humanizados, crítico-reflexivos, que atuem no cuidado individual e coletivo, pesquisa, educação, gestão e organização dos serviços de saúde; que possibilitem a universalização, equidade e a participação social nas ações realizadas (FAMEMA, 2008). Para tanto, considera a integralidade do cuidado, propõe uma prática não dicotomizada, superando a separação do cuidado individual/coletivo, preventivo/curativo e dos campos da saúde pública e da atenção hospitalar, bem como do modelo biomédico. Fundamenta-se na interdisciplinaridade dos saberes, no trabalho em equipe, na lógica da vigilância à saúde e articulação das dimensões biológica, psicológica e social. Sustenta-se em bases que extrapolam para além do domínio técnico da profissão e compromete-se com as necessidades de saúde da população. 
Considerando que foi vanguarda em relação a projetos inovadores na graduação em Enfermagem, enfrentando muitos e superando alguns desafios, acredita-se que é um processo que necessita de monitoramento e, assim sendo, não pode prescindir de constantes avaliações que levem em consideração a proposta emancipatória e que possibilitem a outros sujeitos o olhar sobre esse processo.

Assim, já foram desenvolvidas duas pesquisas de avaliação de resultado do processo de formação de médicos e enfermeiros da Famema, as quais mostraram que esses profissionais estão sendo formados numa perspectiva transformadora das práticas educativa e profissional em saúde (GOMES et al., 2009; BRACCIALLI et al., 2009; HAFNER et al., 2010; HIGA et al., 2013).

Desse modo, o acompanhamento dos egressos contribui para a constante adequação e transformação relacionadas ao mundo do trabalho e para a política nacional de saúde e educação. Além de representar o produto das faculdades, é ponte entre a academia e o mercado de trabalho, e sua desenvoltura nele é um dos parâmetros mais importantes da qualidade do ensino (CARRIJO et al., 2007).

Os resultados podem ser considerados instrumento de gestão, pois permitem monitorar situações que devem ser mudadas, incentivadas ou potencializadas desde o início de uma intervenção até o alcance do que foi pretendido e previsto. Eles podem, ainda, efetuar adequações nos objetivos, metas e até na missão de uma organização, permitindo aos gestores acompanhar todo o processo (MINAYO, 2009).

\section{Objetivos}

O objetivo deste estudo foi possibilitar o acompanhamento dos egressos em relação à sua inserção tanto no mercado de trabalho como na continuidade de sua formação, além de contribuir para a reflexão sobre as relações entre teoria e prática e entre o mundo acadêmico e o mundo do trabalho, subsidiando a avaliação da formação acadêmica.

\section{Metodologia}

Pesquisa de natureza ex-post-facto teve como referência a estruturação de um banco de dados procurando agregar diferentes informações sobre os egressos do Curso de Enfermagem, com um questionário quanti-qualitativo, assegurando um diálogo entre eles.

Os sujeitos da pesquisa foram os egressos do Curso de Enfermagem que se formaram entre os anos de 2007 e 2010, em continuidade à pesquisa anteriormente realizada. A pesquisa foi divulgada, previamente, via $e$-mail, telefone e 
redes sociais, e enviado convite que explicava o objetivo da pesquisa, senha eletrônica de acesso ao questionário disponibilizado, on-line, no site da Famema/ Projeto-Egresso-Enfermagem, para um total de 144 egressos, e o aceite eletrônico do consentimento informado era requerido para dar acesso ao questionário.

Em relação ao instrumento de coleta de dados de natureza quantitativa, foi aplicado um questionário contendo 21 questões relacionadas aos aspectos socioeconômicos, formação continuada, atuação e inserção profissional e avaliação do curso na ótica do egresso. Esse instrumento fora anteriormente validado pela sua aplicação na pesquisa de avaliação do resultado do processo de formação de enfermeiros da Famema (FAMEMA, 2009).

As informações referentes ao item "Avaliação do Curso" constavam de uma escala de resposta com escores que especificavam o nível de concordância com a afirmação sobre a contribuição do curso (discordo totalmente $=1$, discordo $=2$, não concordo nem discordo $=3$, concordo $=4$, concordo totalmente $=5$ ).

Em relação ao instrumento de coleta de natureza qualitativa, foi solicitado ao egresso que fizesse uma narrativa destacando aspectos significativos de sua formação acadêmica e de sua vivência profissional.

Para a análise dos dados, as respostas dos questionários foram codificadas e formatadas em banco de dados. Inicialmente, as informações foram analisadas a partir de frequências absolutas e porcentagens, dispostas em tabelas. As narrativas foram trabalhadas a partir do Método de Interpretação de Sentidos (GOMES et al., 2005).

A pesquisa foi desenvolvida após a aprovação do Comitê de Ética em Pesquisa da Faculdade de Medicina de Marília, sob o $n^{\circ} 784 / 10$, preservando o anonimato dos sujeitos.

\section{Resultados e discussão}

\subsection{Caracterização dos egressos}

Do total de 144 egressos do Curso de Enfermagem, formados entre os anos de 2007 e 2010, convidados a participarem da pesquisa, 46 (32\%) responderam ao questionário enviado. Dos anos de 2007 a 2009, a média foi de $30 \%$ de respondentes/ano, enquanto, do ano de 2010, a taxa de respostas foi de $42 \%$. Vários estudos apontam ser a baixa adesão à resposta um problema característico de pesquisa baseada em questionários, com média de retorno de 30 a $50 \%$ (BÓGUS et al., 2011; KOCK; DORIA FILHO; BOLLELA, 2011; MARTINÉLI et al., 2011), também observado em nosso estudo. Entretanto, a taxa de adesão aumenta quando se investiga uma turma recém-formada, sendo necessária a utilização de novas estratégias para que se tenha uma adesão mais significativa. 
A caracterização dos egressos, foco desta pesquisa, está demonstrada na Tabela 1. Dentre os 46 respondentes, 93\% são do sexo feminino; $80 \%$ estão trabalhando como enfermeiros; $51 \%$ com renda mensal entre dois e quatro salários mínimos (SM); 67\% referem ter apenas um (1) emprego e público, sendo que $47 \%$ exercem uma função assistencial, distribuídos parcialmente entre as áreas de atenção primária (48\%) e atenção secundária/terciária (52\%). A maioria de nossos egressos (91\%) está cursando ou já cursou uma pós-graduação, sendo que $47 \%$ fazem ou fizeram uma especialização.

Vários estudos têm mostrado altas taxas de empregabilidade, com menos de três meses de formado, dos egressos enfermeiros (CARRIJO et al., 2007; MARTINÉLI et al., 2011; PÜSCHEL; INÁCIO; PUCCI, 2009; SANNA; SANTOS, 2003). Quanto à remuneração, semelhante ao nosso estudo, no de Püschel, Inácio, Pucci (2009), essa varia entre três e cinco SM, mas, em contrapartida, nos de Cardoso (2002) e Sanna; Santos (2003), a maioria dos egressos apresentou renda mensal igual ou superior a oito SM, muitos deles advindos do vínculo empregatício com o Programa Saúde da Família (PSF).

Quanto à área de atuação, resultados semelhantes aos nossos foram mostrados com egressos do curso de Enfermagem da FAMERP (MARTINÉLI et al., 2011) e da Faculdade de Medicina do Triângulo Mineiro (CARDOSO, 2002). Diferentemente, Carrijo et al. (2007) mostraram que egressos enfermeiros de Goiânia estavam preferencialmente trabalhando em PSF (69,2\%), enquanto egressos da Escola de Enfermagem da USP (PÜSCHEL; INÁCIO; PUCCI, 2009) e da Universidade Estadual de Londrina (SOUZA, 2000) estavam, na sua maioria, trabalhando em hospitais. Segundo alguns autores, os municípios são os maiores empregadores dos enfermeiros (VIEIRA; AMÂNCIO FILHO; OLIVEIRA, 2004; ANSELMI; DUARTE; ANGERAMI, 2001), entretanto a maior oferta de emprego está na rede hospitalar (SANNA; SANTOS, 2003), principalmente nos grandes municípios.

Em revisão recente, Branquinho (2012) relata que a busca pelo processo de educação continuada é um indicativo de atenção do profissional sobre a importância da sua qualificação para se tornar competitivo diante do mercado de trabalho. Esse fato pode ser detectado pela alta taxa de egressos, mais de $80 \%$, que buscam realizar uma pós-graduação como forma de aperfeiçoamento e crescimento profissional (CARRIJO et al., 2007; MARTINÉLI et al., 2011; PÜSCHEL; INÁCIO; PUCCI, 2009; SOUZA, 2000). Bezerra (2003) ressalta que esse tipo de atitude é esperado e deve ser estimulado pelos gestores que precisam considerar as pessoas como o diferencial para o alcance da qualidade nos serviços. 


\subsection{Avaliação da contribuição do curso de graduação para sua atuação profissional}

Quanto à avaliação feita pelo egresso sobre como ele percebe a preparação que o curso the proporcionou para o exercício profissional, os resultados estão apresentados na Tabela 2. Os escores atribuídos pelo egresso ao avaliar a contribuição do curso para sua formação foram agrupados nas categorias que expressam Concordância (concordo totalmente + concordo); Concordância Indefinida (nem concordo, nem discordo) e Discordância (discordo totalmente + discordo).

Considerando a DCN e o perfil do profissional a ser formado pela Famema, o curso de graduação busca, entre outros aspectos, levar o estudante a aprender a aprender, o que engloba o aprender a ser, o aprender a fazer, o aprender a viver juntos e o aprender a conhecer (DELORS, 2000), além de atender às necessidades sociais da saúde, com ênfase no Sistema Único de Saúde (SUS) e assegurar a integralidade da atenção e a qualidade e a humanização do cuidado no atendimento (BRASIL, 2001).

Nesse sentido, a motivação para a mudança curricular tem como compromisso atender as necessidades de saúde da população, que precisa de cuidados profissionais de enfermagem para produzir uma melhoria efetiva na qualidade da assistência prestada, e obter o reconhecimento da sociedade do seu valor social no cuidado humano (PIRES, 2004).

Ao se analisarem os resultados, a maioria dos egressos concorda que o curso de Enfermagem contribuiu, de forma significativa, para um cuidado humanizado, por meio de diversas estratégias que os prepararam para o exercício de sua prática profissional de modo efetivo. Para tanto, é indispensável a capacidade de identificar as dimensões biológica, psicológica e social de forma integrada; o saber trabalhar com pessoas dos sexos masculino e feminino, com diferentes orientações sexuais; o trabalhar com pessoas em diversas fases da vida; o estabelecer relação enfermeiro-paciente/família/comunidade, mostrando o alto grau de importância que o egresso aponta sobre sua capacidade de relacionar-se com as pessoas como fator essencial para o cuidado humanizado.

Portanto, a educação deve visar tanto ao autoconhecimento como ao conhecimento do outro, em busca de aprender a viver junto e com o outro (DELORS, 2000). Além disso, a educação deve proporcionar a reflexão sobre o preservar a unidade do ser humano, sem esquecer-se de sua complexidade e de sua diversidade, estimulando o graduando a entender que compreender o outro é também aprender e reaprender constantemente (MEIRA; KURCGANT, 2009).

É possível que a integração teoria e prática vivenciada desde o primeiro ano do curso em cenário de aprendizagem, como no PSF, por meio das unidades 
educacionais UPP e UES, tenha favorecido a incorporação de uma prática pautada no cuidado humanizado. Portanto, pode-se dizer que os egressos consideraram que o curso proporcionou o conhecimento necessário para esse cuidado, abrangendo todos os aspectos envolvidos no processo saúde-doença.

Tanto no nível individual quanto no coletivo, os egressos mostraram alto índice de concordância quanto ao preparo que o curso lhes proporcionou para identificar problemas/necessidades de saúde por meio da coleta de dados e para planejar, elaborar e executar o plano de cuidados, exigindo conhecimento adequado que fundamente suas decisões e ações.

O trabalho em equipe tem sido veiculado como estratégia para enfrentar o intenso processo de especialização na área da saúde, que tende a aprofundar verticalmente o conhecimento e a intervenção em aspectos individualizados das necessidades de saúde, sem contemplar, simultaneamente, a articulação das ações e dos saberes (PEDUZZI, 2001). Nesse sentido, os egressos identificam que o currículo da Famema lhes proporcionou as habilidades necessárias para planejar, elaborar e organizar o trabalho em saúde junto à equipe, mostrando alto índice de concordância nesse aspecto.

Entretanto, dois aspectos do currículo, habilidade para resolver um caso ou uma situação não vivenciada e utilizar dados/ferramentas de pesquisa na prática profissional, foram avaliados pelos egressos com os menores índices gerais de concordância.

Em relação à resolução de uma situação não vivenciada durante sua formação (o aprender a aprender), apesar de a maioria apontar concordância, o índice observado de discordância nos leva a refletir se e por que, na opinião de alguns egressos, o curso não forneceu habilidades que o instrumentalizassem na resolução dessas situações. Pode-se inferir que, na prática educativa, a educação é uma forma de intervenção no mundo, assim o processo ensino-aprendizagem pode criar possibilidades para a construção de um conhecimento (FREIRE, 1996). Desse modo, mesmo não tendo certeza do conhecimento adquirido para atuarem na prática, os egressos são capazes de demonstrar capacidade crítica no que tange ao aprender a conhecer, aprender a aprender, no sentido de exercitar seu pensamento, sua atenção e memória, selecionando as informações que podem ser contextualizadas em relação à realidade que vivenciaram (ANTUNES, 2001).

Comparando esta avaliação das turmas de 2007 a 2010 com a anteriormente realizada das turmas de 2001 a 2006 (HIGA et al., 2013), não houve diferença de percepção dos egressos quanto à contribuição que o curso lhes proporcionou para o exercício profissional tanto em relação ao cuidado humanizado como ao cuidado bem fundamentado. 
Estudos realizados com egressos enfermeiros da Faculdade de Medicina do Triângulo Mineiro (CARDOSO, 2002) e da Universidade Federal de Santa Catarina (GHIORZI; RIBEIRO; FENILLI, 1995) apontaram para a necessidade de melhoria da qualidade de ensino em relação à integração curricular, maior investimento em pesquisa, além de problemas relacionados às contradições entre o discurso e a prática e entre a visão de integralidade do ser humano e a formação não contextualizada.

Este estudo constatou que a percepção do egresso sobre a preparação profissional proporcionada pelo curso foi, em sua maioria, positiva, traduzindo uma adequação do curso aos pressupostos curriculares e às DCN para o curso de Enfermagem, o que proporcionou as aptidões necessárias para a segurança e boa atuação do profissional enfermeiro formado pela Famema.

\subsection{Análise qualitativa}

Ao analisar as narrativas dos egressos, percebeu-se que eles consideraram o Curso de Enfermagem bastante satisfatório do ponto de vista do processo ensino-aprendizagem, apesar de apresentar algumas fragilidades. Após a análise, foram identificadas duas temáticas não excludentes entre si: Os pressupostos curriculares identificados no cotidiano dos egressos e Os métodos ativos de ensino-aprendizagem enquanto caminho de transformação, as quais são descritas a seguir:

\subsubsection{Os pressupostos curriculares identificados no cotidiano dos egressos}

Ao se pensar nos processos de mudança na formação, delinearam-se os princípios e as bases que ancoraram a proposta pedagógica, sendo elas o processo de trabalho no SUS, métodos ativos de ensino-aprendizagem e currículo integrado, que foram identificados por meio das narrativas no cotidiano do trabalho dos egressos.

Nessas narrativas, observou-se que, apesar de a formação enfocar preferencialmente a atenção primária, permitiu a inserção dos egressos em todos os níveis de atenção e em diversos cenários, bem como favoreceu o desenvolvimento do trabalho em equipe e da humanização do cuidado, conforme ilustrado nos depoimentos a seguir:

Vemos a prática dos saberes entre indivíduos/equipe multiprofissional, que possibilita ao egresso a adaptação a diversos serviços, com atitudes assertivas e ativas. (E1) 
Avaliação da formação de enfermeiros: o reflexo dos métodos de ensino-aprendizagem e pressupostos curriculares na prática profissional

Possibilitou que eu tivesse ferramentas para trabalhar em diversas áreas como primária, secundária e terciária além de desenvolver capacidade para participar do gerenciamento de uma unidade de saúde. (E29)

A promulgação da Constituição Brasileira de 1988 que assegurou a saúde como direito de todos e dever do Estado, criou o Sistema Único de Saúde (SUS) com a proposta de universalidade, equidade, integralidade, descentralização e participação social. Esse movimento refletiu em ações conjuntas dos Ministérios da Saúde e Educação culminando com as Diretrizes Curriculares Nacionais para os diversos cursos da área da saúde, inclusive o curso de Enfermagem, com o objetivo de reorientar a formação desses profissionais segundo o trabalho para o SUS e focado nas necessidades da população (BRASIL, 1988; 2001; CECCIM; FEUERWERKER, 2004).

A partir da implementação do SUS, organizado em torno da vigilância à saúde, muitas modificações foram necessárias para a organização das práticas de atenção e de gestão do sistema de saúde e, consequentemente, exigiu processos de mudança na natureza do trabalho, sendo necessários a qualificação dos trabalhadores e novos paradigmas que norteassem a formação profissional (CHIESA et al., 2007; SILVA; SOUZA; FREITAS et al., 2011).

Conforme preconiza as DCN, a formação do profissional da área da saúde deve estar em consonância com o SUS, preparando-os especialmente para atuar na atenção básica, trabalhar em equipe e voltado à atenção integral à saúde (CHIESA et al., 2007).

Nessa perspectiva, há a necessidade de focar na valorização dos sujeitos envolvidos no processo ensino-aprendizagem tanto da academia quanto do serviço de saúde onde ocorrem as atividades práticas, buscando as potencialidades de cada um na construção do conhecimento. O papel da escola é incentivar o estudante a construir seu processo de aprendizagem de forma autônoma, considerando a realidade em que está inserido, visando o desenvolvimento das competências necessárias ao trabalho em saúde (CHIESA et al., 2007).

A proposta da Famema busca então superar os modelos tradicionais predominantes e desarticulados para aproximar a formação das necessidades da população. Entretanto se depara com um grande desafio que, segundo Chiesa et al. (2007), passa pelo desenvolvimento de novas concepções do processo saúde-doença, educação, ser humano e sociedade, utilizando metodologias ativas no processo ensino-aprendizagem aplicadas a situações reais que contribuam para a atuação contextualizada, crítica e participativa do futuro profissional.

Se o desafio para a consolidação do SUS que ainda persiste é o de mobilizar o envolvimento do cidadão, lidar com as desigualdades e focar a integralidade 
do cuidado, a formação de profissionais diretamente envolvidos com o esse sistema continua mobilizando esforço no sentido de prepará-los para serem agentes de transformação.

Ao analisar as narrativas dos egressos, observou-se que, apesar dos desafios, as bases de sustentação do currículo da Famema estão presentes em seu cotidiano, conforme ilustrado a seguir:

A graduação prepara e contribui muito para lidarmos com todos os tipos de situações, tanto no cuidado individual quanto no coletivo e na gestão. Isso se deve principalmente à integração dessas esferas e do biopsicossocial durante a aprendizagem prática. (E22)

Entretanto, ainda se depara com egressos que encontram dificuldades devido a essa prática ser contra-hegemônica, conforme observado na seguinte narrativa:

Faço uma ressalva que os referenciais teóricos adotados pela Instituição e os quais estudei durante grande parte do curso não foram muito bem utilizados, ou seja, aplicados em concursos que almejava. Acredito que, por se tratar de uma nova perspectiva e uma imagem-objeto que no momento ainda não são valorizadas tanto pelo modelo de formação tradicional quanto pelo modo de produção capitalista, torna-se frequentemente um desamparo na $4^{a}$ série, época em que temos contato com processos seletivos e concursos públicos. (E33)

Segundo Câmara et al. (2012), apesar de os profissionais da saúde terem a informação sobre o conceito ampliado de saúde, ainda a percebem como o oposto de doença e trabalham nesse enfoque. O modelo assistencial e o processo de trabalho ainda estão estruturados focalizando a doença, e todas as ações estão centradas no seu enfrentamento.

Além desse foco na doença o mercado de trabalho ainda está sustentado na lógica biomédica e tecnicista, exigindo um profissional com um perfil tradicionalista e diferente daquele preconizado para o trabalho no SUS e o proposto pelo curso de Enfermagem da Famema.

Em relação à concepção curricular, observou-se, nos depoimentos dos egressos, que a formação sustentada num currículo integrado favoreceu o cotidiano de sua atuação enquanto profissional, possibilitando o planejamento e execução de melhorias nos processos de trabalho. 
Durante a graduação não percebia a amplitude de tudo o que estava aprendendo e hoje, atuando na área, entendo a dimensão disso. Diariamente sou desafiada para desempenhar minha função de Coordenadora de Unidades de Internação de um hospital privado... Consigo aplicar na assistência o conhecimento adquirido e planejar/executar melhorias para os processos de trabalho das nossas equipes. Isso reflete na assistência aos pacientes e familiares. (E34)

No currículo integrado, o estudante é conectado à vida cotidiana, no caso, os serviços de saúde e a comunidade, e, a partir das experiências vivenciadas, por meio de sucessivas aproximações, apreende o que está ocorrendo e o que pode "fazer com os problemas identificados, como pode intervir numa dada realidade enquanto profissional de enfermagem em formação" (FAMEMA, 2008, p.32), com uma organização de conteúdos de forma interdisciplinar e metodologias baseadas na investigação cooperativa (TORRES SANTOMÉ, 1997).

Nas últimas décadas, exige-se do trabalhador a capacidade de diagnóstico, de solução de problemas, de tomar decisões, de intervir no processo de trabalho, de trabalhar em equipe, de se auto-organizar e enfrentar situações em constantes mudanças. Desse modo, o currículo integrado favorece a formação profissional com esse perfil (DELUIZ, 2001), e o currículo de Enfermagem da Famema vem corroborando essa formação quando traz em sua organização a inserção do estudante na prática desde o primeiro ano do curso, organizando seus conteúdos de forma interdisciplinar.

A fala dos egressos aponta que a inserção precoce na prática durante a graduação ajuda na atuação profissional.

A prática vivenciada desde o início da graduação, sendo inserida nos diversos serviços de saúde e a possibilidade de fazer os eletivos voluntários e obrigatórios, proporcionou viver a prática do enfermeiro desde o início da graduação.... (E14)

Apesar de explicitar no currículo um perfil profissional "generalista, humanizado, crítico-reflexivo, que atue com responsabilidade social e compromisso com a cidadania" (FAMEMA, 2008, p. 38), ainda se identificam equívocos do egresso quanto ao seu entendimento, conforme depoimento a seguir:

Atualmente estou realizando especialização em Auditoria no Instituto Albert Einstein e percebi a necessidade de ter um enfoque maior na 
graduação, muitas ferramentas de qualidade, auditoria de contas, tanto no SUS como privado, poderiam ser abordadas durante o curso. (E31)

No Curso de Enfermagem da Famema, outro aspecto do currículo integrado é ser orientado por competência, optando pela construção da formação a partir do mundo do trabalho, adotando a abordagem dialógica que propõe:

[...] o diálogo da formação entre o mercado de trabalho e a universidade, articulando a teoria e a prática, buscando que o estudante mobilize/construa seu desempenho na ação de forma pertinente e no momento oportuno para solucionar os problemas e as necessidades de saúde nos cenários de aprendizagem em que se encontra (FAMEMA, 2008, p. 35).

Roldão (2005) aponta que a capacidade de mobilização e articulação pertinente e oportuna dos recursos necessários para atuar diante de uma situação seria a própria essência da competência. Portanto, não se trata apenas da aplicação dos recursos, mas da sua construção frente a uma dada situação da prática profissional, de acordo com o grau de autonomia e domínio do estudante no momento de sua formação.

Quando vivenciei algumas situações no emprego, me lembrei de situações vivenciadas na prática durante a graduação, sendo mais fáceis de serem resolvidas e de serem praticadas. Tudo isso atribuo ao método e aos professores que tive na Famema, sendo fundamentais para o meu sucesso e crescimento profissional. (E10)

\subsubsection{Os métodos ativos de ensino-aprendizagem enquanto caminho de transformação}

Foi identificada, nas narrativas dos egressos, a importância dos métodos ativos de ensino e aprendizagem tanto na sua formação acadêmica quanto na sua atuação e atualização profissional:

A metodologia utilizada pela Famema também contribui após a graduação. Todo esse processo de conhecimento acerca de materiais, fonte de informação para a aprendizagem facilitam a atualização de conhecimento, o que é importantíssimo no processo de cuidado. (E23) 
As metodologias de ensino ativo têm maior adequação ao perfil de profissional que se exige atualmente, uma vez que incentiva a busca ativa de informações, o trabalho em equipe e em pequenos grupos, favorecendo a análise crítica das situações vivenciadas.

As ações educativas desenvolvidas na Famema têm como finalidade "preparar os indivíduos para a ação social, articulando os propósitos educacionais às necessidades políticas, sociais, individuais e coletivas da população" (FAMEMA, 2008, p. 28). Meira, Kurcgant (2009) destacaram que a formação do enfermeiro deve envolver a capacidade de atuar e promover a responsabilidade social e o compromisso com a cidadania, além de promover a reflexão e transformação da realidade.

Na Famema, existe uma preocupação constante em promover a aprendizagem significativa, o aprender a aprender, a busca de atualização e do conhecimento.

Nós nunca aprendemos tudo durante a graduação, de forma que deparei com situações que não vivenciei ou estudei durante a graduação. O método de ensino me auxiliou a buscar e a pesquisar de forma que hoje entendo o significado de aprendizagem significativa e valorizo muito a forma de ensino da Famema, com PBL e problematização. (E19)

Na concepção da Aprendizagem Baseada em Problemas (ABP), o processo ensino- aprendizagem é direcionado para o desenvolvimento da capacidade do estudante de construir seu próprio conhecimento, articulando-o aos seus saberes prévios com o estímulo proporcionado pelos problemas de saúde-doença, desenvolvendo e utilizando o raciocínio crítico e habilidades de comunicação para a resolução de problemas clínicos, e de entender a necessidade de aprender sempre (GOMES et al., 2009).

O processo de aprender deve deflagrar no estudante uma curiosidade crescente, tornando-o mais e mais criador. Quanto mais exercemos esse processo, mais construímos e desenvolvemos a capacidade de aprender a aprender para transformar a realidade e nela intervir.

Na problematização, outro método ativo proposto no Projeto Pedagógico do Curso, baseado na Pedagogia Crítica de Paulo Freire, o conhecimento é elaborado a partir do processo de ação-reflexão-ação, considerando a rede de determinantes contextuais, as implicações pessoais e as interações entre os diferentes sujeitos que aprendem e ensinam (BATISTA et al., 2005). Portanto, na problematização, a relação ação-reflexão-ação transformadora é o eixo básico de orientação da aprendizagem. 
Aponto como aspectos importantes o processo de ação-reflexão-ação utilizada durante [a graduação] e consequentemente durante a minha prática profissional, além da reflexão sobre o processo de trabalho e mudança nas práticas necessárias para o cuidado. Percebo também que o graduando desenvolve autonomia durante o processo.... (E33)

Apesar das potencialidades do método ativo relatadas pelos egressos, eles apontaram que, ao ingressarem no curso, ainda encontravam-se imaturos, e isso, somado ao método pedagógico aplicado, trouxe dificuldades de adaptação.

Ao adentrar a faculdade todos somos ainda imaturos devido ao desenvolvimento normal do ser humano e, diante disso, o método aplicado para cada um buscar o próprio conhecimento diante das situações enfrentadas não condiz com a realidade, é preciso um suporte maior do que a facilitação, ou talvez uma transição entre as aulas tradicionais e a facilitação que é aplicada. (E40)

A compreensão sobre esse dado pode estar relacionada à formação prévia desses estudantes que tiveram contato, em sua formação, quase que exclusivamente com o modelo de ensino tradicional, que se sustenta pela retenção de informações, memorização e avaliações que não favorecem seu processo formativo (ANGELI; LOUREIO, 2001), como também pode relacionar-se ao perfil com o qual ingressam, sendo que geralmente procedem de escolas particulares, com bom nível sociocultural, o que envolve capacidade intelectual e cognitiva, somada às características típicas do adolescente, e que foram sempre acompanhados e cuidados. Nesse contexto, a exposição ao ambiente educacional universitário se constitui como uma experiência de amadurecimento. Oferece aos estudantes a possibilidade de problematizar as suas experiências e consequentemente identificar a complexidade do ser adulto, porém precisam de um tempo de adaptação, de um processo de aprendizagem (DALTRO; PONDE, 2011).

Outro aspecto abordado nas narrativas dos egressos foi referente ao trabalho em pequenos grupos, permitindo troca de ideias e uma construção coletiva de conhecimentos.

Gostei de estudar no método PBL, porque também me ajudou a ter maior facilidade de falar na frente de outras pessoas e me ajudou a ser menos fechada, sendo mais fácil hoje realizar palestras educativas. (E43) 
Considerando a formação de enfermeiros proposta pela Famema, apoiada nas DCN e visando à formação de profissionais voltados para o SUS, este se torna um pressuposto para a integralidade das ações de saúde, ou seja, um "orientador para a reorganização do processo de trabalho nos serviços de saúde com vista a transformações nas formas de agir sobre os fatores que interferem no processo saúde-doença da população a partir de uma maior interação entre os profissionais e as ações que desenvolvem" (COSTA; ENDERS; MENEZES, 2008, p. 530).

Ainda para os egressos, os métodos ativos de ensino e aprendizagem permitiram tanto a inserção no mercado de trabalho como na pós-graduação (especialização, residência, mestrado/doutorado), embora algumas instituições de saúde ainda exijam experiência profissional, dificultando a inserção no mercado de trabalho:

Minha inserção no mercado de trabalho após a graduação foi muito rápida, passando por aprimoramento profissional e após concurso público, que está abrindo portas para docência. Esta trajetória está diretamente relacionada ao que aprendi e vivenciei durante a graduação. Cada cenário, seja de prática, seja de discussão, contribuiu para meu desenvolvimento profissional e pessoal. (E19)

A inserção no mercado de trabalho foi bem dificil por as empresas, em sua maioria, exigirem experiência profissiona”. (E3)

Apesar de os egressos apontarem que o currículo favorece o raciocínio clínico e crítico, a humanização do cuidado e resolver situações não vivenciadas na graduação, sinalizam que houve deficiência do aprendizado de técnicas/ procedimentos:

Durante o curso de graduação tivemos a oportunidade de aprender a procurar novas informações e conhecimentos, porém, no que diz respeito à técnica de procedimentos de enfermagem, ficou a desejar principalmente na saúde do adulto, o que nos é mais demandado na prática do dia a dia. (E42)

Os egressos, ao apontarem a fragilidade na aprendizagem em relação aos conhecimentos técnicos e aos instrumentais necessários à prática, levam à reflexão se o currículo proposto tem formado para a atuação do enfermeiro, visto que as referidas práticas fazem parte do seu trabalho. Há de se considerar que pode 
estar sendo dado, de acordo com Silva e Senna (2006), destaque às questões sociais e políticas, com prejuízo ao desenvolvimento das habilidades técnico-científicas e da "clínica em saúde", continuando um modelo fragmentado.

Aparece ainda, como fragilidade, a deficiência na pesquisa e sistema de informação e maior informação sobre o mercado de trabalho.

Acredito que o incentivo à pesquisa cientifica na Famema merece ser levada em consideração e o investimento nesta área é de extrema importância, percebo que em outras instituições públicas essa área de competência é mais incentivada por parte dos docentes aos discentes. (E21)

No Projeto Pedagógico do Curso de Enfermagem da Famema, existe a proposição de desenvolvimento do Trabalho de Conclusão de Curso (TCC) pelo estudante, cujo propósito é de realizar um projeto de pesquisa contendo todos os passos do método científico, atividade esta não considerada pelos egressos como estímulo à pesquisa. Além disso, nos últimos dois anos, a Famema passou a contar com dois programas de pós-graduação, com o Programa de Educação pelo Trabalho para a Saúde e Programa Institucional de Bolsas de Iniciação Científica, possibilitando aos professores envolverem estudantes de graduação nas atividades científica, tecnológica, profissional e artístico-cultural.

\section{Considerações finais}

Ao realizar um diálogo entre os resultados da análise quantitativa e os da qualitativa, observou-se que há congruência entre eles, o que permitiu validar tais resultados. Em comparação a avaliação anterior (HIGA et al., 2013) observamos que, na visão dos egressos, o curso continua proporcionando aos mesmos uma formação adequada para o exercício da pratica profissional humanizada.

Observou-se que os pressupostos curriculares estão presentes no cotidiano dos egressos e que os métodos ativos de ensino-aprendizagem bem como as premissas do currículo integrado e orientado por competência profissional favorecem seu constante desenvolvimento na profissão.

Algumas fragilidades apontadas que merecem atenção e investimentos são a dificuldade de adaptação às metodologias de ensino empregadas, a deficiência no aprendizado de procedimentos técnicos e pouco estímulo à pesquisa, cabendo ao colegiado do Curso, nos momentos destinados à revisão curricular, especial atenção a elas e planejamento de estratégias para superá-las e, assim, reafirmar seu compromisso com a formação profissional e com a qualidade de vida da população. 
As avaliações que permearam a percepção do egresso sobre a fundamentação do cuidado, uma atribuição inerente à profissão, abrangeram diferentes etapas do processo de adquirir conhecimento prático-cognitivo e mostraram uma tendência para reconhecer a efetividade do curso em proporcionar essa habilidade.

Entretanto, se a proposta do curso é a integralidade do cuidado e a vigilância em saúde, as narrativas não deixam claro o modelo de cuidado desenvolvido pelos egressos. O mesmo observa-se em relação ao desenvolvimento do trabalho em equipe de saúde, onde o egresso destaca apenas a contribuição do curso para a habilidade de comunicação.

Foi apontada, como fragilidade, a proposta do curso em formar profissionais comprometidos com os princípios do SUS, modelo este considerado pelos egressos, contra hegemônico ao processo de trabalho vigente e a seus modos de produzir saúde.

Nossa avaliação é que o curso proporciona recursos para a formação de um profissional reflexivo, entretanto não garante que o mesmo seja um agente transformador, considerando o contexto e a realidade sociopolítica em que ele se insere, aspecto este que precisa ser mais bem trabalhado com os estudantes durante a graduação com vista à transformação.

Além disso, apesar do currículo do curso de Enfermagem da Famema estar direcionado à competência profissional, garantindo uma aproximação a essa prática desde o primeiro ano do curso, somente essa proposta de mudança na academia parece não garantir a integralidade do cuidado ao indivíduo assistido, a partir de um sistema de saúde que considere a equidade e as necessidades da população local. Ainda nos deparamos com cuidados especializados, falta de equipes que se responsabilizem pelo cuidado integral aos indivíduos, desarticulação entre as redes de cuidado e forte questão cultural em relação ao conceito saúde, onde os sujeitos envolvidos - usuários e profissionais - continuam entendendo saúde como ausência de doença.

Se após todos esses anos de conquistas de um sistema de saúde mais justo e para todos, ainda enfrentamos desafios que parecem não avançar no sentido de uma verdadeira transformação social, a formação dos profissionais de saúde está distante do modelo de atenção integral que se pretende no SUS. E para além das questões técnicas - abrangendo conhecimentos e habilidades - a formação precisa envolver mudanças nas relações e nas pessoas. Talvez precisaremos ir além da formação de um estudante crítico e reflexivo para um estudante ativo que demonstre ações transformadoras às necessidades de saúde da população e ao sistema de saúde onde ele está inserido, independentemente de estar na atenção primária ou secundária/terciária. 
Tabela 1 - Características sociodemográficas, inserção no mercado de trabalho e educação continuada

\begin{tabular}{|c|c|c|}
\hline Características & Estatística & $\mathrm{n}^{*}$ \\
\hline $\begin{array}{l}\text { Mulheres } \\
\text { Está atualmente trabalhando }\end{array}$ & $43(93 \%)$ & $\begin{array}{l}46 \\
46\end{array}$ \\
\hline Sim & $37(80 \%)$ & \\
\hline Não & $09(20 \%)$ & \\
\hline Número de trabalhos que possui & & 46 \\
\hline Zero & $07(15 \%)$ & \\
\hline Um & $31(67 \%)$ & \\
\hline Dois & $05(11 \%)$ & \\
\hline Três ou mais & $03(7 \%)$ & \\
\hline Características do trabalho & & 45 \\
\hline Público & $30(67 \%)$ & \\
\hline Privado & $12(27 \%)$ & \\
\hline Autônomo & $03(6 \%)$ & \\
\hline Áreas de atuação & & 42 \\
\hline Atenção primária & $20(48 \%)$ & \\
\hline Atenção secundária e terciária & $22(52 \%)$ & \\
\hline Função que exerce nos locais de trabalho & & $60^{* *}$ \\
\hline Assistencial & $28(47 \%)$ & \\
\hline Gerencial & $11(18 \%)$ & \\
\hline Chefia/docência & $07(12 \%)$ & \\
\hline Outras & $14(23 \%)$ & \\
\hline Cursou ou está cursando pós-graduação & & 46 \\
\hline Sim & $42(91 \%)$ & \\
\hline Não & $04(9 \%)$ & \\
\hline Tipo de pós-graduação & & 42 \\
\hline Aprimoramento & $02(5 \%)$ & \\
\hline Especialização & $20(47 \%)$ & \\
\hline Mestrado & $04(10 \%)$ & \\
\hline Doutorado & $04(10 \%)$ & \\
\hline Residência & $12(28 \%)$ & \\
\hline Trabalho como enfermeiro forma remunerada & & 46 \\
\hline Sim & $37(80 \%)$ & \\
\hline Não & $09(20 \%)$ & \\
\hline Rendimentos de outras fontes & & 46 \\
\hline Sim & $12(26 \%)$ & \\
\hline Não & $34(74 \%)$ & \\
\hline Renda Mensal *** & & 45 \\
\hline$<2 \mathrm{SM}$ & 05 (11\%) & \\
\hline 2-4 SM & $23(51 \%)$ & \\
\hline 4-6 SM & $12(27 \%)$ & \\
\hline$>6 \mathrm{SM}$ & $06(11 \%)$ & \\
\hline
\end{tabular}

* $\mathrm{n}=$ número de indivíduos que responderam ao item

** número de citações

${ }^{* * *}$ salário mínimo $(\mathrm{SM})$ paulista $=\mathrm{R} \$ 710,00$ 


\begin{tabular}{|c|c|c|c|c|c|c|c|c|c|c|c|c|}
\hline $\begin{array}{l}\frac{0}{\pi} \\
\frac{\pi}{2} \\
\frac{0}{0} \\
.0 \\
\frac{0}{0}\end{array}$ & 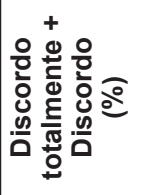 & : & $\begin{array}{l}10 \\
0 \\
0\end{array}$ & $\stackrel{\circ}{\text { i }}$ & $\stackrel{\circ}{\circ}$ & O & $\stackrel{\circ}{i}$ & O & $\stackrel{\circ}{\sim}$ & O. & $\stackrel{\circ}{\leftarrow}$ & O) \\
\hline 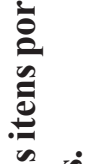 & 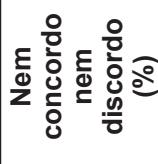 & : & $\begin{array}{l}0 \\
0 \\
0\end{array}$ & $\stackrel{\circ}{i}$ & O. & O. & $\stackrel{\circ}{\circ}$ & $\stackrel{\circ}{\circ}$ & $\begin{array}{l}10 \\
0 \\
0\end{array}$ & $\stackrel{\circ}{\circ}$ & $\stackrel{\circ}{\stackrel{M}{\sim}}$ & $\stackrel{\circ}{\stackrel{\circ}{\circ}}$ \\
\hline 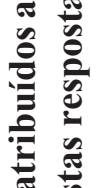 & 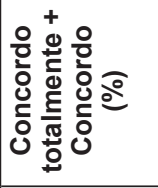 & $\begin{array}{l}0 \\
\stackrel{0}{\circ}\end{array}$ & $\begin{array}{l}\text { O } \\
\text { s. }\end{array}$ & ஜ̈ & $\begin{array}{l}\circ \\
\text { ¿ }\end{array}$ & $\begin{array}{l}0 \\
\stackrel{0}{\circ}\end{array}$ & $\begin{array}{l}\circ \\
\text { ơ }\end{array}$ & $\begin{array}{l}\circ \\
\ddot{8}\end{array}$ & $\frac{n}{\sigma}$ & $\begin{array}{l}\text { ष्. } \\
\mathscr{8}\end{array}$ & $\begin{array}{l}0 \\
0 \\
0\end{array}$ & $\begin{array}{l}0 \\
\text { o. } \\
1\end{array}$ \\
\hline 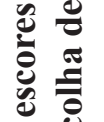 & 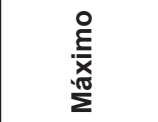 & 10 & 10 & م & L & 10 & م & ما & م & م & م & 10 \\
\hline 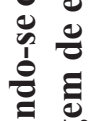 & 号 & $\nabla$ & $N$ & $N$ & $\nabla$ & $\nabla$ & $N$ & $m$ & $N$ & $m$ & $N$ & $N$ \\
\hline 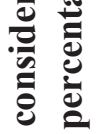 & $\begin{array}{l}\frac{\pi}{\sigma} \\
\frac{\pi}{\pi} \\
\sum^{\frac{\pi}{2}}\end{array}$ & م) & 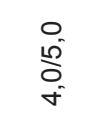 & $\begin{array}{l}0 \\
\text { in } \\
\text { o } \\
\text { i }\end{array}$ & : & 웅 & 요 & 우 & : & $\stackrel{\circ}{\circ}$ & $\stackrel{\circ}{\circ}$ & $\stackrel{\circ}{+}$ \\
\hline & $=$ & $\mathscr{\sigma}$ & $\stackrel{\varphi}{+}$ & $\stackrel{0}{+}$ & $\stackrel{0}{+}$ & $\stackrel{\varphi}{+}$ & $\mathscr{q}$ & $\mathscr{P}$ & $\mathscr{\varphi}$ & $\stackrel{\odot}{\leftrightarrow}$ & $\stackrel{\varphi}{\forall}$ & $\stackrel{\varphi}{+}$ \\
\hline 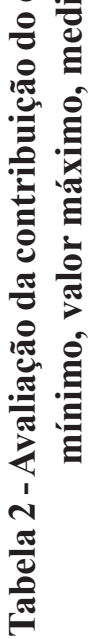 & 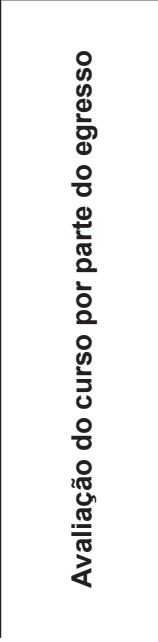 & 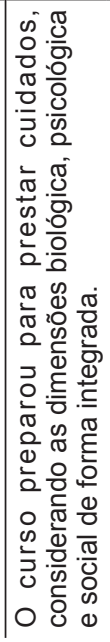 & 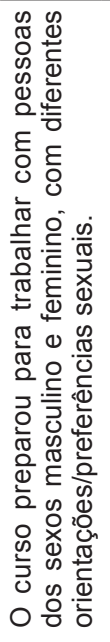 & 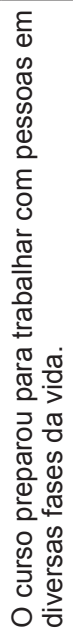 & 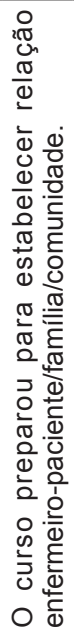 & 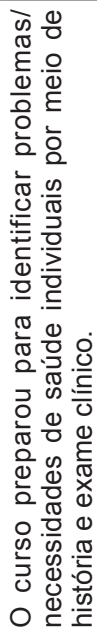 & 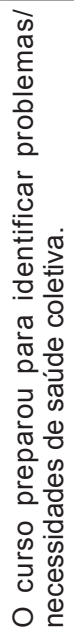 & 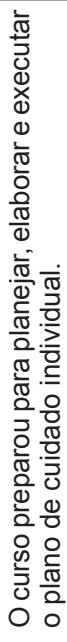 & 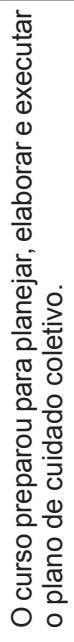 & 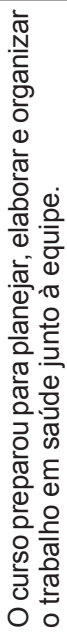 & 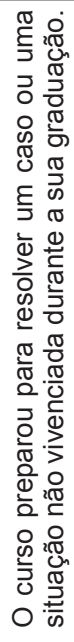 & 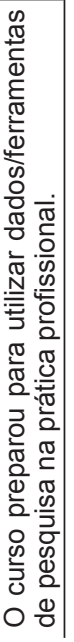 \\
\hline
\end{tabular}




\section{Referências}

ANGELI, O. A.; LOUREIRO, S. R. A aprendizagem baseada em problemas e os recursos adaptativos de estudantes do curso médico. Rev. Bras. Educ. Med., Rio de Janeiro, v. 25, n. 2, p. 32-41, 2001.

ANSELMI, M. L.; DUARTE, G. G.; ANGERAMI, E. L. S. 'Sobrevivência' no emprego dos trabalhadores de enfermagem em uma instituição hospitalar pública. Rev. Latino-Am. Enfermagem, Ribeirão Preto, v. 9, n. 4, p. 1-8, 2001.

ANTUNES, C. Como desenvolver as competências em sala de aula. 5. ed. Petrópolis: Vozes, 2001.

BATISTA, N. et al. O enfoque problematizador na formação de profissionais da saúde. Rev. Saúde Pública, São Paulo, n. 39, v. 2, p. 231-7, 2005.

BEZERRA, A. L. Q. O contexto da educação continuada em enfermagem. São Paulo: Lemar e Martini, 2003.

BÓGUS, C. M.; BERSUSA, A. A. S.; MARTINS, C. L.; ESCUDER, M. M. L. Conhecendo egressos do curso técnico de Enfermagem do PROFAE. Rev. Esc. Enferm. USP, São Paulo, v. 45, n. 4, p. 945-52, 2011.

BRACCIALLI, L. A. D.; MARVULO, M. M. L.; GOMES, R.; MORAES, M. A. A.; ALMEIDA FILHO, O. M.; PINHEIRO, O. L.; HAFNER, M. L. M. B. Cuidado ampliado em enfermagem. Revista Mineira de Enfermagem (REME), Belo Horizonte, v. 13, n. 3, p.391-8, 2009.

BRANQUINHO, N. C. S. S. Egressos do Curso de Graduação da Faculdade de Enfermagem da Universidade Federal de Goiás: perfil profissiográfico, mercado de trabalho e atuação profissional. 2012. Dissertação (Mestrado) - Faculdade de Enfermagem, Universidade Federal de Goiás, Goiânia, 2012.

BRASIL. Constituição. Constituição da República Federativa do Brasil. Brasília: Senado Federal, 1988.

BRASIL. Ministério da Educação. Conselho Nacional de Educação. Parecer CNE/CES 1.133/2001, de 7 de agosto de 2001: Diretrizes curriculares 
nacionais dos cursos de graduação em enfermagem, medicina e nutrição. Brasília, 2001. Disponível em: <http://www.mec.gov.br/Sesu/diretriz.shtm>. Acesso em: 29 mar. 2013.

CÂMARA, A. M. C. S.; MELO, V. L. C.; GOMES, M. G. P.; PENA, B. C.; SILVA, A. P.; OLIVEIRA, K. M.; MORAES, A. P. S.; COELHO, G. R.; VICTORINO, L. R. Percepção do processo saúde-doença: significados e valores da educação em saúde. Rev. Bras. Educ. Med., Rio de Janeiro, v. 36 , n. 1, p. 40-50, 2012.

CARDOSO, R. J. Egressos do centro de graduação em Enfermagem da Faculdade de Medicina do Triângulo Mineiro: sua formação e trajetória profissional. 2002. Tese (Doutorado) - Escola de Enfermagem de Ribeirão Preto, Universidade de São Paulo, Ribeirão Preto, 2002.

CARRIJO, C. I. S.; BEZERRA, A. L. Q.; MUNARI, D. B.; MEDEIROS, M. A empregabilidade de egressos de um curso de graduação em Enfermagem. Rev. Enferm., Rio de Janeiro, v. 15, n. 3, p. 356-63, 2007.

CHIESA A. M. et al. Formação de profissionais da saúde: aprendizagem significativa à luz da promoção da saúde. Cogitare Enferm., Curitiba, v. 12, n. 2, p. 236-40, 2007.

CECCIM, R. B.; FEUERWERKER, L. C. M. O quadrilátero da formação para a área da saúde: ensino, gestão, atenção e controle social. Physis, Rio de Janeiro, v. 14, n. 1, p. 41-65, 2004.

COSTA, R. K. S.; ENDERS, B. C.; MENEZES, R. M. P. Trabalho em equipe de saúde: uma análise contextual. Cienc. Cuid. Saude, Maringá, v. 7, n. 4, p. 530-6, 2008.

DALTRO, M. R.; PONDE, M. P. Atenção psicopedagógica no ensino superior: uma experiência inovadora na graduação de medicina. Constr. Psicopedag., São Paulo, v. 19, n. 18, p. 104-23, 2011.

DELORS, J. et al. Educação: um tesouro a descobrir: Relatório para a UNESCO da Comissão Internacional sobre Educação para o século XXI. 4. ed. São Paulo: Cortez, 2000.

DELUIZ, N. Qualificação, competências e certificação: visão do mundo do trabalho. Formação, Brasília, v. 1 n. 2, p. 5-15, maio 2001. 
FAMEMA - FACULDADE DE MEDICINA DE MARÍLIA. Relatório da pesquisa de avaliação de resultado do processo de formação de médicos da Famema. Marília, 2008.

FAMEMA - FACULDADE DE MEDICINA DE MARÍLIA. Relatório da pesquisa de avaliação de resultado do processo de formação de enfermeiros da Famema. Marília, 2009.

FREIRE, P. Pedagogia da autonomia: saberes necessários à prática educativa. 29. ed. São Paulo: Paz e Terra. 1996.

GHIORZI, A. R.; RIBEIRO, E. M.; FENILLI, R. M. O currículo, o curso e a profissão, na visão de egressos da graduação em Enfermagem da UFSC. Texto Contexto Enferm., Florianópolis, v. 4, p. 69-91, 1995.

GOMES, R. et al. Organização, processamento, análise e interpretação de dados: o desafio da triangulação. In: MINAYO, M. C. S.; ASSIS, S. G.; SOUZA, E. R. (Org.). Avaliação por triangulação de métodos: abordagem de programas sociais. Rio de Janeiro: Fiocruz, 2005. p. 185-221.

GOMES, R.; FRANCISCO, A. M.; TONHOM, S. F. R.; COSTA, M. C. G.; HAMAMOTO, C. G.; PINHEIRO, O. L.; MOREIRA, H. M.; HAFNER, M. L. M. B. A formação médica ancorada na aprendizagem baseada em problema: uma avaliação qualitativa. Interface - Comunicação, Saúde e Educação, Botucatu, v. 13, n. 28, p.71-83, 2009.

HAFNER, M. L. M. B.; MORAES, M. A. A.; MARVULO, M. M. L.; BRACCIALLI, L. A. D.; CARVALHO, M. H. R.; GOMES, R. A formação médica e a clínica ampliada: resultados de uma experiência brasileira. Rev. Ciênc. Saúde Coletiva, Rio de Janeiro, v. 15, supl. 1, p.1715-24, 2010.

HIGA, E. F. R.; GOMES, R.; CARVALHO, M. H. R.; GUIMARÃES, A. P. C; TAIPEIRO, E. F.; HAFNER, M. L. M. B.; RIBEIRO, S. M. Percepção do egresso de enfermagem sobre a contribuição do curso para o exercício do cuidado. Texto Contexto Enferm., Florianópolis, v. 22, n, 1, p. 97-105, 2013.

KOCH, V. H. K.; DORIA FILHO, U.; BOLLELA, V. R. Avaliação do programa de residência médica do Departamento de Pediatria da Faculdade de Medicina da Universidade de São Paulo. Rev. Bras. Educ. Med., Rio de Janeiro, v. 35, n. 4, p. 454-9, 2011. 
Avaliação da formação de enfermeiros: o reflexo dos métodos de ensino-aprendizagem e pressupostos curriculares na prática profissional

MARTINÉLI, D. D.; MOURA, C. R.; CESARINO, C. B.; BECCARIA, L. M.; PINTO, M. H.; PASCHOAL, V. A. Avaliação do currículo da graduação em Enfermagem por egressos. Cogitare Enferm., Curitiba, v. 16, n. 3, p. 524-9, 2011.

MEIRA, M. D. D.; KURCGANT, P. Avaliação de curso de graduação segundo egressos. Rev. Esc. Enferm. USP, São Paulo, v. 43, n. 2, p. 481-5, 2009 .

MINAYO, M. C.S. Construção de indicadores qualitativos para avaliação de mudanças. Rev. Bras. Educ. Med., Rio de Janeiro, v. 33 n. 1 (supl. 1), p. 83-91, 2009.

PEDUZZI, M. Equipe multiprofissional de saúde: conceito e tipologia. Rev. Saúde Pública, São Paulo, v. 35, n. 1, p. 103-9, 2001.

PIRES, D. Organização do trabalho em Enfermagem: implicações no fazer e viver dos trabalhadores de nível médio. Trab. Educ. Saúde, Rio de Janeiro, v. 2, n. 2, p. 311-25, 2004.

PÜSCHEL, V. A. A.; INÁCIO, M. P.; PUCCI, P. P. A. Inserção dos egressos da Escola de Enfermagem da USP no mercado de trabalho: facilidades e dificuldades. Rev. Esc. Enferm. USP, São Paulo, v. 43, n. 3, p. 535-42, 2009.

ROLDÃO, M. C. Para um currículo do pensar e do agir: as competências enquanto referencial de ensino e aprendizagem no ensino superior. In: WORKSHOP UNIVERSIDADE DE AVEIRO, 2005, Aveiro. Competência e avaliação. Aveiro, 2005. Disponível em: <http://www1.ci.uc.pt/pessoal/ abade/bolonha/docs/Competencias_roldao.pdf> Acesso em: 19 mar. 2013.

SANNA, M. C.; SANTOS, C. E. Inserção no mercado de trabalho dos egressos do curso de graduação em Enfermagem da Universidade de Santo Amaro. Rev. Paul. Enferm., São Paulo, v. 22, n. 3, p. 255-60, 2003.

SILVA K. L., SENA R. R. A educação de enfermagem: buscando a formação crítico-reflexiva e as competências profissionais. Rev. Latino-Am. Enfermagem, Ribeirão Preto, v. 14, n. 5, p. 755-61, 2006.

SILVA, M. J.; SOUSA, E. M. FREITAS, C. L. Formação em enfermagem: interface entre as diretrizes curriculares e os conteúdos de atenção básica. Rev. Bras. Enferm., Brasília, v. 64, n. 2, p. 315-21, 2011. 
SOUZA, S. N. D. H. O egresso do curso de graduação em enfermagem da Universidade Estadual de Londrina: perfil socioeconômico-demográfico, inserção no mercado de trabalho, atuação profissional e contribuição do curso. 2000. Dissertação (Mestrado) - Escola de Enfermagem, Universidade de São Paulo, São Paulo, 2000.

TORRES-SANTOMÉ, J. A instituição escolar e a compreensão da realidade: o currículo integrado. In: SILVA, L. H.; AZEVEDO, J. C.; SANTOS, E. S. (Org.). Novos mapas culturais, novas perspectivas educacionais. Porto Alegre: Sulina, 1997. p. 58-74.

VIEIRA, A. L. S.; AMÂNCIO FILHO, A.; OLIVEIRA, E. S. Mercado de trabalho em saúde na região sudeste-Brasil: a inserção da equipe de enfermagem. Rev. Latino-Am. Enfermagem, Ribeirão Preto, v. 12, n. 1, p. $1-6,2004$.

Anete Maria Francisco - Faculdade de Medicina de Marília Marília | SP | Brasil. Contato: anetemf@gmail.com

Maria Cristina Guimarães da Costa - Faculdade de Medicina de Marília Marília | SP | Brasil. Contato: mcgcosta@superig.com.br

Cássia Galli Hamamoto - Faculdade de Medicina de Marília Marília | SP | Brasil. Contato: cghamamoto@yahoo.com.br

Maria de Lourdes Marmorato Botta Hafner - Faculdade de Medicina de Marília | Marília | SP | Brasil. Contato: maude@famema.br

Artigo recebido em 15 de agosto de 2013 e aprovado em 22 de agosto de 2014. 